\title{
Availability and characteristics of cardiac rehabilitation programmes in China
}

\author{
Zixin Zhang, ${ }^{1}$ Quinn Pack, ${ }^{2,3}$ Ray W Squires, ${ }^{2}$ Francisco Lopez-Jimenez, ${ }^{2}$ Lujiao Yu, ${ }^{1}$ \\ Randal J Thomas ${ }^{2}$
}

- Additional material is available. To view please visit the journal online (http://dx. doi.org/10.1136/heartasia2016-010758).

${ }^{1}$ Division of Cardiology, The First Affiliated Hospital of China Medical University, Shenyang, China

${ }^{2}$ Cardiovascular Health and Rehabilitation Program, Division of Cardiovascular Diseases and Internal Medicine, Mayo Clinic and Foundation, Rochester, Minnesota, USA ${ }^{3}$ Division of Cardiology, Department of Medicine, Baystate Medical Center and Tufts University School of Medicine, Springfield, Massachusetts, USA

\section{Correspondence to}

Dr Randal J Thomas, Cardiovascular Health and Rehabilitation Program, Division of Cardiovascular Diseases and Internal Medicine, Mayo Clinic and Foundation, 200 First Street, SW, Rochester, MN 55905, USA:

thomas.randal@mayo.edu

Received 7 April 2016 Revised 11 May 2016 Accepted 12 May 2016

\section{ABSTRACT \\ Objective Cardiac rehabilitation (CR) improves patient outcomes in cardiovascular disease (CVD), but little is known about its current practice in China. Since China has a high CVD burden, the potential impact of CR is large. We surveyed large hospitals in China to assess the prevalence and characteristics of CR.}

Methods We carried out a cross-sectional survey of 454 large medical centres in China to ascertain the prevalence of $C R$, perceived barriers to $C R$ and various other characteristics of centres with and without $C R$ programmes.

Results Responses were received from 124 (27\%) of the 454 centres surveyed. Of these, only $30(24 \%)$ reported having an operating CR programme. This was true, despite the near universal availability of advanced imaging, coronary stenting and other technologies. Overall, the estimated availability of CR programmes was about 2 programmes per 100 million inhabitants. Centres with CR were more likely than centres without $C R$ to be university or government hospitals, have more inpatient cardiovascular beds and provide secondary CVD prevention services. Perceived barriers to $C R$ included a lack of awareness, training and experience in $C R$, as well as limited resources for a CR programme. Respondents suggested that educational and training activities could help promote greater implementation of CR in China.

Conclusions The availability of CR is low (24\%) in the large medical centres in China we surveyed, highlighting the importance of efforts to raise awareness of the benefits of $C R$, to provide $C R$ training to healthcare professionals and to improve $C R$ availability throughout China.

\section{INTRODUCTION}

There is growing evidence that cardiac rehabilitation (CR) is a cost-effective and highly beneficial method of delivering secondary prevention services, resulting in decreased cardiovascular morbidity and mortality in patients with cardiovascular disease (CVD). ${ }^{1-4}$ Unfortunately, CR usage is suboptimal and has significant geographical variability in the USA, with close correlation between CR participation and local availability of CR programmes. ${ }^{5}$ Usage of $\mathrm{CR}$ in parts of Europe, Canada, Australia and Latin America is also suboptimal and variable, ${ }^{6-10}$ but little is known about the availability and use of CR in China, the most populous country in the world.

The aim of our study was to carry out a national survey of the largest hospitals in China in order to identify the availability, predictors and characteristics of operational CR programmes.

\section{METHODS}

We carried out an email-based survey of 454 (51\%) of the 899 largest (level IIIA) hospitals in China, identified from a list of hospitals through the Ministry of Health of the People's Republic of China (now called the National Health and Family Planning Commission of the People's Republic of China). We contacted the chief of cardiology at each hospital and asked him/her to participate in the survey. Email addresses of the chiefs of cardiology were obtained from the communication directories of Chinese national cardiovascular conferences and from the list of corresponding author email addresses in major Chinese and international medical journals. If we had not received a response to the email survey after 2 weeks, we re-sent the request. If we still had not received a response after 2 additional weeks, an alternative physician leader was identified at that same hospital and was sent the survey request. If the alternative physician did not respond after two requests, we considered that hospital to be a 'non-respondent'. Consent was obtained from each respondent and the project was approved by the Mayo Clinic Institutional Review Board. We provided to each respondent a brief DVD on CR produced by the Mayo Clinic, as a small token of appreciation and as an incentive to participate in the survey.

The survey included three components: (1) a 36-item survey of basic hospital and staff characteristics, (2) respondents who reported having an active CR programme were asked to complete a second survey about how they had developed, implemented and maintained their CR programme and (3) respondents from centres without CR programmes were sent a second survey about potential barriers to the development, implementation and maintenance of a CR programme.

Finally, an abbreviated version of the original survey was sent to non-respondents that included 6 of the original 36 survey items that helped ascertain whether or not the hospital had an operating CR programme.

Content and face validity of the survey items were assessed by the coauthors, who have experience in both survey research and CR. All survey questions were translated into Chinese by one of the investigators (ZZ). That translation was reviewed and approved by the Mayo Clinic Language Services Department.

Prevalence of CR programmes was estimated from responses to the surveys. Using the initial 36-item survey, we performed univariate analysis to find those factors that differed significantly between the hospitals with $\mathrm{CR}$ and those without CR. 
Significant univariate factors were then assessed using multivariate logistic regression to identify which if any characteristics were independently associated with the presence of CR. Statistical analysis was performed with SPSS V.13.0 (SPSS, Chicago, IL, USA). Due to the limited sample size, frequencies were compared with non-parametric Mann-Whitney U test. A two-sided $p$ value of $<0.05$ was considered to be statistically significant.

\section{RESULTS}

We received completed surveys from 124 (27\%) of the 454 hospitals surveyed. Sixty per cent of respondents were cardiology department chairs or vice-chairs. The full 36-item survey was returned by $74(60 \%)$ respondents, while 50 (40\%) additional respondents who had failed to return the full survey completed the shorter 6-item survey. Thirty (24\%) of the 124 participating hospitals reported having an active CR programme. Twenty-nine per cent $(18 / 62)$ of the participating government hospitals, 22\% $(12 / 54)$ of the university-based hospitals and $0 \%(0 / 8)$ of the military hospitals reported an active CR programme. Of the 13 hospitals that finished the complete 36-item survey and reported having a CR programme, 3 (23\%) offered only inpatient CR, 3 (23\%) offered only outpatient CR and 7 (54\%) offered both inpatient and outpatient CR services. Table 1 shows the CR programme density by region (see online supplementary figures S1-S3 for additional details). The number and density of CR programmes were greatest in regions 2 (North), 3 (East) and 5 (South), and were lowest in regions 1 (Northeast), 4 (Central), 6 (Southwest) and 7 (Northwest), with region 7 reporting no CR programmes. Overall, the estimated density of CR programmes in China is approximately $2 \mathrm{CR}$ programmes for every 100 million inhabitants.

Table 2 shows various characteristics of the responding hospitals with and without CR programmes. Hospitals with CR had a higher ratio of cardiology beds to total inpatient beds, and were more likely than non-CR hospitals to have special preventionrelated clinics, such as weight loss clinics. A very high percentage of hospitals, with or without CR, reported performing common cardiovascular procedures, including percutaneous coronary intervention (PCI), coronary artery bypass graft surgery (CABG) and heart valve surgery. However, more hospitals without CR reported performing heart transplantation than hospitals with

Table 1 Distribution of hospitals with CR programmes, population and $\mathrm{CR}$ density by region in China

\begin{tabular}{llll}
\hline Region & $\begin{array}{l}\text { Number of } \\
\text { hospitals with } \\
\text { CR }\end{array}$ & $\begin{array}{l}\text { Population } \\
\text { (in millions) }\end{array}$ & $\begin{array}{l}\text { Density of CR programmes } \\
\text { per 100 million inhabitants }\end{array}$ \\
\hline 1 & 1 & 108 & 0.9 \\
2 & 9 & 155 & 5.8 \\
3 & 13 & 382 & 3.4 \\
4 & 2 & 240 & 0.8 \\
5 & 4 & 147 & 2.7 \\
6 & 1 & 213 & 0.5 \\
7 & 0 & 99 & 0 \\
Total & 30 & 1344 & 2.2 \\
\hline
\end{tabular}

Regions in China include the following: (1) Northeast China (Heilongjiang, Jilin and Liaoning), (2) North China (Beijing, Tianjin, Hebei, Shanxi, Inner Mongolia), (3) East China (Shanghai, Shandong, Jiangsu, Anhui, Jiangxi, Zhejiang, Fujian), (4) Central China (Hubei, Hunan, Henan), (5) South China (Guangdong, Guangxi, Hainan), (6) Southwest China (Chongqing, Sichuan, Guizhou, Yunnan, Tibet) and (7) Northwest China (Shaanxi, Gansu, Ningxia, Xinjiang, Qinghai).

$\mathrm{CR}$, cardiac rehabilitation.
Table 2 Characteristics of hospitals with and without CR programmes

\begin{tabular}{|c|c|c|c|}
\hline Item & $\begin{array}{l}\text { Hospitals with } \\
\text { CR } \\
(n=13)(\%)\end{array}$ & $\begin{array}{l}\text { Hospitals } \\
\text { without CR } \\
(\mathrm{n}=61)(\%)\end{array}$ & $\mathrm{p}$ Value \\
\hline \multicolumn{4}{|c|}{ Ratio of number of beds (CV department/total) } \\
\hline$\leq 5 \%$ & 0 & $20(32.8)$ & 0.016 \\
\hline $5 \%-10 \%$ & $10(76.9)$ & $33(54.1)$ & 0.133 \\
\hline$\geq 10 \%$ & $3(23.1)$ & $8(13.1)$ & 0.363 \\
\hline \multicolumn{4}{|l|}{ Tests and services provided } \\
\hline MRI & $13(100)$ & $58(95.1)$ & 0.417 \\
\hline CTA & $13(100)$ & $59(96.7)$ & 0.511 \\
\hline NCIT & $9(69.2)$ & $45(73.8)$ & 0.740 \\
\hline Echocardiography & $13(100)$ & $61(100)$ & 1.000 \\
\hline ABPM & $12(92.3)$ & $59(96.7)$ & 0.467 \\
\hline $\begin{array}{l}\text { Special clinic for } \\
\text { hypertension }\end{array}$ & $10(76.9)$ & $48(78.7)$ & 0.889 \\
\hline $\begin{array}{l}\text { Special clinic for lipid } \\
\text { disorders }\end{array}$ & $9(69.2)$ & $27(44.3)$ & 0.104 \\
\hline $\begin{array}{l}\text { Special clinic for tobacco } \\
\text { cessation }\end{array}$ & $8(61.5)$ & $25(41.0)$ & 0.179 \\
\hline $\begin{array}{l}\text { Special clinic for weight } \\
\text { loss }\end{array}$ & $8(61.5)$ & $16(26.2)$ & 0.014 \\
\hline Special clinic for diabetes & $11(84.6)$ & $54(88.5)$ & 0.697 \\
\hline $\begin{array}{l}\text { Special clinic for sleep } \\
\text { disorders }\end{array}$ & $9(69.2)$ & $29(47.5)$ & 0.158 \\
\hline Psychiatry/psychology clinic & $10(76.9)$ & $39(63.9)$ & 0.372 \\
\hline Physical rehabilitation clinic & $11(84.6)$ & $37(60.7)$ & 0.103 \\
\hline $\begin{array}{l}\text { Special clinic for nutrition } \\
\text { counselling }\end{array}$ & $6(46.2)$ & $23(37.7)$ & 0.574 \\
\hline \multicolumn{4}{|c|}{ Types of cardiology procedures performed } \\
\hline Coronary angiography & $13(100)$ & $61(100)$ & 0.417 \\
\hline $\mathrm{PCl}$ & $13(100)$ & $61(100)$ & 0.511 \\
\hline CABG & $12(92.3)$ & $58(95.1)$ & 0.740 \\
\hline Placement of ICD & $12(92.3)$ & $50(82.0)$ & 1.000 \\
\hline $\begin{array}{l}\text { Placement of CRT and } \\
\text { CRTD }\end{array}$ & $10(76.9)$ & $52(85.2)$ & 0.467 \\
\hline RF ablation therapy & $13(100)$ & $56(91.8)$ & 0.889 \\
\hline Heart valve surgery & $12(92.3)$ & $51(83.6)$ & 0.104 \\
\hline CHD surgery & $11(84.6)$ & $50(82.0)$ & 0.179 \\
\hline Heart transplantation & $3(23.1)$ & $18(29.5)$ & 0.014 \\
\hline \multicolumn{4}{|c|}{ Number of PCI procedures performed (in 2011) } \\
\hline $100-300$ & $3(23.1)$ & $13(21.3)$ & 0.889 \\
\hline $301-500$ & $1(7.7)$ & $13(21.3)$ & 0.258 \\
\hline $501-1000$ & $5(38.5)$ & $11(18.0)$ & 0.107 \\
\hline $1001-3000$ & $4(30.8)$ & $22(36.1)$ & 0.718 \\
\hline$\geq 3001$ & 0 & $2(3.3)$ & 0.551 \\
\hline \multicolumn{4}{|c|}{ Number of CABG procedures performed (in 2011) } \\
\hline 0 & $2(15.4)$ & $13(21.3)$ & 0.632 \\
\hline $1-50$ & $5(38.5)$ & $21(34.4)$ & 0.783 \\
\hline $51-200$ & $4(30.8)$ & $17(27.9)$ & 0.834 \\
\hline $201-500$ & $1(7.7)$ & $10(16.4)$ & 0.426 \\
\hline$\geq 501$ & $1(7.7)$ & 0 & 0.030 \\
\hline
\end{tabular}

Bold denotes statistical significance at $(p<0.05)$.

ABPM, Ambulance Blood Pressure Monitoring; $C A B G$, coronary artery bypass graft surgery; CHD, congenital heart disease; CR, cardiac rehabilitation; CRT, cardiac resynchronisation treatment; CRTD, cardiac resynchronisation treatment and defibrillation; CTA, computer tomography angiography; CV, cardiovascular; ICD, implantable cardiac defibrillator; NCIT, nuclear cardiology imaging tests; $\mathrm{PCl}$, percutaneous coronary intervention; RF, radiofrequency.

CR (29.5\% vs 23.1\%, p=0.014). Of note, all hospitals with CR and more than $95 \%$ of hospitals without CR reported the availability of services involving advanced technologies, including MRI and computed tomographic angiography. Likewise, a high 
percentage of all hospitals reported the availability of advanced cardiology technologies and treatments, including PCI, CABG, defibrillator placement, cardiac resynchronisation treatment and radiofrequency ablation therapy. Long-term follow-up of 1 year or longer was significantly more common in hospitals with $\mathrm{CR}$ compared with those without CR programmes $(79 \%$ vs $33 \%$, $\mathrm{p}=0.02$ ).

All CR programmes reported offering a clinical assessment of patients at programme entry, periodic blood tests to assess cardiovascular risk factors and counselling for physical activity, exercise training, nutrition, smoking cessation and adherence to preventive medications. Weight management services and blood pressure monitoring and treatment were offered by $92 \%$ of CR programmes, while $85 \%$ of CR programmes offered lipid management, $69 \%$ offered psychological counselling and management, $46 \%$ offered sleep apnoea screening and management and 39\% offered depression screening and management. Most CR programmes reported that they had been in operation for a relatively short time period, with $52 \%$ of programmes reported being in operation for 2 years or less, and $41 \%$ reporting that they had been in operation for $2-5$ years. Less than $7 \%$ had been in operation for more than 10 years.

All CR programmes reported using physicians to help with the operations of their programme, $85 \%$ reported using nurses as well, $46 \%$ reported using dieticians and $<20 \%$ reported using exercise specialists and other types of healthcare professionals (see online supplementary table S3). All programmes reported caring for post-PCI and heart failure patients, 92\% reported caring for patients following myocardial infarction or pacemaker implantation, $69 \%$ reported caring for patients following CABG or heart valve surgery and $62 \%$ reported caring for patients with stable congenital heart disease, including patients with stable angina. Of the three hospitals with CR that reported performing heart transplantation surgery, only one reported caring for post-transplantation patients in their CR programme.

Perceived barriers to implement $\mathrm{CR}$ programme were reported by respondents from 92 hospitals without CR. The most common barrier to $\mathrm{CR}$ implementation was the lack of staff members with interest, experience and training in CR. Additional barriers that were reported include financial limitations, space limitations and lack of patient awareness of $\mathrm{CR}$ (see online supplementary table S4). Potential solutions to CR implementation in China were suggested by respondents from 13 hospitals with CR, including the provision of education and training to hospital staff members who, in turn, could provide $\mathrm{CR}$ services in their hospital. Other potential solutions included raising awareness of the benefits of CR among patients, physicians and healthcare leaders, and increasing collaboration and cooperation within specific hospitals and regions to establish systematic approaches to $\mathrm{CR}$ referral for eligible patients. Efforts to promote governmental policy and financial support for $\mathrm{CR}$ were also mentioned as potential solutions to CR implementation (see online supplementary table S5). Among hospitals without CR programmes, $12 \%$ reported that they were likely to implement a CR programme in their hospital in the coming year.

\section{DISCUSSION}

From this national survey of large hospitals in China, we found that $24 \%$ have operational CR programmes, resulting in a low density of CR programmes throughout China-approximately 2 programmes for every 100 million inhabitants, significantly lower than most countries (eg, 10 CR programmes per 100 million inhabitants in the USA and 500 programmes per 100 million inhabitants in Brazil). ${ }^{11}$ Components of the CR programmes in China are similar to those reported in other countries, including in the USA, ${ }^{12}$ Canada, ${ }^{13}$ the Middle East ${ }^{13}$ and South America. ${ }^{10}$ Hospitals with CR programmes had more hospital beds devoted to cardiovascular care (more than $5 \%$ of the total hospital beds), and were more likely to have long-term CVD patient follow-up programmes than hospitals without CR. Nearly all CR programmes (90\%) reported using only physicians and nurses for their CR staffing needs, but relatively few used other healthcare professionals who are potentially more cost-effective in the CR setting, such as exercise physiologists, dieticians or physical therapists. This suggests the need to provide more cost-effective staffing models through training and delivery model redesign.

While many countries in the world report a gap in the referral of eligible patients to existing CR programmes, ${ }^{14}{ }^{15}$ our results suggest an even greater 'upstream' challenge in China-a lack of available CR programmes throughout China to which eligible patients could potentially be referred. This gap in China is similar to but larger than the gap in CR programme availability reported previously in Latin America. ${ }^{7}$ One study of Latin American and Caribbean hospitals found that only 56\% of hospitals that were surveyed reported having operational CR programmes, compared with the $24 \%$ of hospitals we found in China that reported having operating CR programmes.

Although CR programme availability was low in the hospitals we surveyed, a high percentage of respondents reported that their hospitals provided advanced, complex medical and/or surgical procedures and technologies, including PCI, defibrillator implantation, radio frequency catheter ablation and MRI. This paradoxical finding - that resources appear to be available for 'higher tech' services, but not for 'lower tech' services like CR, is important, is similar to reports from other parts of the world, ${ }^{10}$ and is a call to policy makers to re-evaluate healthcare funding priorities. At the same time, this paper is a call to CR healthcare professionals in China and throughout the world to develop, validate and implement models of CR delivery that would be feasible and cost-effective. Clearly, the relative cost of CR delivery models in high-income countries is not feasible in low-income and middle-income countries. ${ }^{16}$

Our study has several limitations, including the small sample size due to a relatively low response rate in our survey cohort. The low response rate for our survey may reflect a low level of familiarity and/or interest in CR in China, or a possible limitation of the effectiveness of our email survey strategy. Given the limitation in survey responses, it is possible that our estimates of $\mathrm{CR}$ availability (prevalence) in China are skewed and inaccurate. Furthermore, we selectively sampled only larger hospitals in China, assuming that they would be more likely to have CR programmes than smaller hospitals. However, this assumption may be incorrect, and may have led to inaccurate estimates of CR prevalence in China. Finally, since it is possible that non-respondents were less likely than respondents to have CR programmes in their hospitals, it is possible that our assessment overestimates the true prevalence of CR programmes in China.

In conclusion, 24\% of major hospitals in China report that they have an operating CR programme. Barriers and potential solutions appear to revolve around the provision of appropriate training of CR professionals who can carry out CR in their hospitals. In addition, there is a need to provide education to raise awareness of the benefits of $\mathrm{CR}$ to patients and health providers throughout China. Through these efforts, there is a hope that 
CR can be implemented more widely throughout China and thereby provide the benefits of $\mathrm{CR}$ services to the growing number of eligible patients in China who have CVD.

\section{Key messages}

What is already known about this subject?

No previous studies have been published on this topic - the prevalence and predictors of cardiac rehabilitation (CR) programmes in major hospitals in China.

What does this study add?

Cardiovascular disease (CVD) prevalence and its consequences are rising in China at a staggering rate. CR programmes are a cost-effective and high value strategy to help reduce mortality and morbidity rates among persons with CVD, but their availability in China has not been studied previously. This study sheds important light on the relative scarcity of CR programmes in China, and helps identify those hospitals in China that have successfully started such programmes.

\section{How might this impact on clinical practice?}

This paper will help stimulate greater awareness of the lack of CR programmes in China and promote greater interest in the dissemination of CR programmes throughout China in the coming years. The clinical impact is potentially huge for China, the populous country in the world, as it searches for ways to deal with the growing number of persons with CVD.

\section{Twitter Follow Randel Thomas at @DrRandalThomas}

Contributors The design of the study was carried out by all authors. Data collection and analysis were performed by ZZ, LY and RJT. Composition and editing of the paper were carried out by all authors. Funding was obtained for the study by RJT, through the Mayo Clinic Division of Cardiovascular Diseases.

Funding Funding was provided for survey and statistical support through the Cardiovascular Division, Department of Medicine, Mayo Clinic, Rochester, Minnesota, USA.

Competing interests None declared.

Provenance and peer review Not commissioned; externally peer reviewed.
Data sharing statement Supplementary tables and figures are provided for online access, if the editors choose to provide them to readers.

\section{REFERENCES}

1 Goel K, Lennon RJ, Tilbury RT, et al. Impact of cardiac rehabilitation on mortality and cardiovascular events after percutaneous coronary intervention in the community. Circulation 2011;123:2344-52.

2 Hammill BG, Curtis LH, Schulman KA, et al. Relationship between cardiac rehabilitation and long-term risks of death and myocardial infarction among elderly Medicare beneficiaries. Circulation 2010;121:63-70.

3 Lavie CJ, Milani RV. Cardiac rehabilitation and exercise training in secondary coronary heart disease prevention. Prog Cardiovasc Dis 2011;53:397-403.

4 Lawler PR, Filion KB, Eisenberg MJ. Efficacy of exercise-based cardiac rehabilitation post-myocardial infarction: a systematic review and meta-analysis of randomized controlled trials. Am Heart J 2011;162:571-84.

5 Suaya JA, Shepard DS, Normand SL, et al. Use of cardiac rehabilitation by Medicare beneficiaries after myocardial infarction or coronary bypass surgery. Circulation 2007:116:1653-62.

6 Buttery AK, Carr-White G, Martin FC, et al. Limited availability of cardiac rehabilitation for heart failure patients in the United Kingdom: findings from a national survey. Eur J Prev Cardiol 2014;21:928-40.

7 Korenfeld Y, Mendoza-Bastidas C, Saavedra L, et al. Current status of cardiac rehabilitation in Latin America and the Caribbean. Am Heart J 2009;158:480-7.

8 McDonall J, Botti M, Redley B, et al. Patient participation in a cardiac rehabilitation program. J Cardiopulm Rehabil Prev 2013;33:185-8.

9 Tiller $S$, Leger-Caldwell L, O'Farrell P, et al. Cardiac rehabilitation: beginning at the bedside. J Cardiopulm Rehabil Prev 2013;33:180-4.

10 Cortes-Bergoderi M, Lopez-Jimenez F, Herdy AH, et al. Availability and characteristics of cardiovascular rehabilitation programs in South America. J Cardiopulm Rehabil Prev 2013;33:33-41.

11 Turk-Adawi K, Sarrafzadegan N, Grace SL. Global availability of cardiac rehabilitation. Nat Rev Cardiol 2014;11:586-96.

12 Balady GJ, Williams MA, Ades PA, et al. Core Components of Cardiac Rehabilitation/Secondary Prevention Programs: 2007 Update: a scientific statement from the American Heart Association Exercise, Cardiac Rehabilitation, and Prevention Committee, the Council on Clinical Cardiology; the Councils on Cardiovascular Nursing, Epidemiology and Prevention, and Nutrition, Physical Activity, and Metabolism; and the American Association of Cardiovascular and Pulmonary Rehabilitation. Circulation 2007;115:2675-82.

13 Turk-Adawi Kl, Terzic C, Bjarnason-Wehrens B, et al. Cardiac rehabilitation in Canada and Arab countries: comparing availability and program characteristics. BMC Health Serv Res 2015;15:521-31.

14 Clark AM, King-Shier KM, Duncan A, et al. Factors influencing referral to cardiac rehabilitation and secondary prevention programs: a systematic review. Eur J Prev Cardiol 2013;20:692-700.

15 Clark AM, King-Shier KM, Spaling MA, et al. Factors influencing participation in cardiac rehabilitation programmes after referral and initial attendance: qualitative systematic review and meta-synthesis. Clin Rehabil 2013;27:948-59.

16 Oldridge NB, Pakosh MT, Thomas RJ. Cardiac rehabilitation in low- and middle-income countries: a review on cost and cost-effectiveness. Int Health 2016;8:77-82. 